\title{
Epigenetic psychiatry: potential of the pre-emptive adaptation
}

\author{
Robert Skopec* \\ Researcher-Analyst, Dubnik, AXON, Slovakia
}

\begin{abstract}
These proteins sense the stress in the environment and connect them to the molecular mechanism promoting the mutations. New data are confirming the regulation of mutagenesis not by stress, but by the given stress responses, when cells are maladapted to their environment and try this way to benefit from mutations. The mutations can allow the cell to adapt. These findings may be used to build new discipline of the epigenetic psychiatry as the potential for the pre-emptive adaptation. It will include also to study cancer as the Entropy in Human Brain Networks.
\end{abstract}

\section{Introduction}

We put together the pieces of a puzzle about the constancy or randomness of mutagenesis that drives evolution by discovery of mutation pathways activated by stress responses of cells maladapted to their environment [1]. It has been shown that the mutation rate may be increased in response to stress (starvation, antibiotics, and other environmental challenges). It is changing paradigm about constant and gradual growing of mutations over time. Some mutations are destructive, but others may promote survival. The mutagenic part of the process is not required to repair the broken DNA strands during removing "error-prone" DNA copying enzyme or polymerase. From the network of 93 genes more than a half are funnelling into 3 nodes going down the mutagenesis pathway. Large fractions of this network go upstream of the activation of the stress response [2].

\section{Materials and methods}

Recent findings indicate that double-strand break (DSB)-repairdependent stress-induced mutation driven by spontaneous DNA breaks is a pathway that cells use as a major source of spontaneous mutation. Mechanisms coupling mutagenesis to stress responses allow cells to evolve rapidly and responsively to their environment [3]. Bacterial and human cells use mechanisms that induce mutation pathways under the control of stress responses. The stress-induced mutagenesis (SIM) is an evolutionary engine which generates the epigenetic diversity. This process causes a switch from high-fidelity to mutagenic DSB repair under RpoS general-stress-response activator-inducing stress. RpoS is activated by general stressors, like starvation, osmotic shock, cold shock, and oxidative stress, making DSB-dependent SIM potentially decisive for producing epigenetic diversity. Furthermore, stress is not required, activation of the stress response is sufficient. The mutagenesis occurs only in stressed cells and in unstressed growing cells if the RpoS response is activated artificially. Coupling of inducible mutagenesis pathways to a general stress response as RpoS causes that epigenetic diversity is generated responsively to different stressors and environments. Stress-induced mutagenesis and phenotypic diversification also contribute to climate/heat stress-induced increased expression of epigenetic variation causing rapid evolution [1,4].
The problem is, that recently we are at new turning point with our existing methodology. During the past 30 years of above evolution methods of awareness and screening have lead to an emphasis on early diagnoses of cancer and not only cancer [5].

Also the goals based on early diagnoses of cancer not reduced the level of late-stage disease and decrease cancer mortality. Recent trends and clinical trials show that these goals have not been met. International data demonstrate significant increase in early stage disease, without a proportional decrease in later-stage disease $[5,6]$.

For me it means that we must re-formulate the definition of pathologic condition of cancer. We need to more differentiate in methodology because cancers are heterogeneous with multiple paths, not all of which progress to metastases and death. This broader definition of disease named cancer must include also indolent disease that causes no harm during patients lifetime. Complexity of possible forms of cancers means that we must try to work with more broad frame of its early diagnosis [7]. Methodological turning-point require to adapt cancer screening to higher analytical level of identifying and treating of epigenetical and psychiatric conditions associated with disease, morbidity and mortality. For example, screening of breast cancer and prostate cancer detect more cases of cancer than are potentially clinically insignificant. The detection and lesions removal in breast cancer considered precancerous frequently not lead to lower incidence of invasive cancer [5]. Over diagnosis and overtreatment results in billions of USD wasted money.

\section{Results}

To replace the invasive methodology in cancer diagnosis we

Correspondence to: Robert Skopec, Researcher-Analyst, Dubnik, AXON, Slovakia, Tel: +421908220692; E-mail: zxcbnvm7@gmail.com

Key words: Epigenetic psychiatry, mutagenesis, stress responses, adaptation, entropy, human brain networks

Received: January 03, 2017; Accepted: January 27, 2017; Published: January 31, 2017 
must put more atention on genealogy of disease development by using more the methodology of epigenetic and psychiatric analysis. Diagnosis of the disease can no longer ignore the social conditions of the patients, because it is known that social stress have adverse health effects on both humans and primates. Additionally, social stress has a strong and pervasive effect on the regulation of the genome. Now researchers found differences in the expression of nearly 1,000 genes in the white blood cells of macaques, which play a role in the immunity. Although all of the monkeys have the same set of genes in their white blood cells, not all of them turn on these genes to the same degree. We are now able to predict the social ranking of a macaque with 80 percent accuracy simply by looking at the genes $[4,8]$. The research showed that if macaque's social rank changed, her gene expression did as well. If an individual is able to improve social environment, the genome may follow this change in pretty plastic way. In this process is found contribution of DNA methylation levels to these effects, and identified global associations between dominance rank and methylation profiles that suggest epigenetic flexibility in response to status-related behavioral cues $[4,9]$.

The potential for psychiatric regulation is supported by correlations between social integration, early-life socioeconomic status (SES), and gene expression variation in humans. Gene-environment interactions in humans and nonhuman primates frequently include allelic variants that act via altering gene expression levels. These evidence lines suggests that social status might also directly influence gene regulation in primates. Recently is known relationship between dominance rank and another mechanism that mediate social environmental effects on the genome, DNA methylation $[4,10]$. In this connection is important peripheral blood mononuclear cell (PBMC) gene expression data $\left(\mathrm{CD} 4^{+}\right.$, $\mathrm{T}$ cells, $\mathrm{B}$ cells, $\mathrm{CD}^{+}$, and monocytes) alone predict social status with $80 \%$ accuracy. In chronic stress exposure is disregulated hypothalamicpituitary adrenal axis (HPA) axis activity. DNA methylation is a regulatory mechanism linked to social environmental effects and gene expression [3,11-14].

A strong and widespread association between dominance rank and gene regulation in PBMCs show sensitivity to social environment reflected in changes in gene expression in the immune system. There is a link between neural, endocrine and immune function. These results support the idea that changes in gene regulation are given by links between the social environment and physiology. Potentially they are supplying an important piece to the puzzle of how social effects regulate the human health, for example in the context of cancer [6]. Some findings suggest that the timescale for social effects on epigenetic variations also extends to adulthood. Such effects include the components of social structure, like the dominance rank $[15,16]$. For example, $N R 3 C 1$, the GC receptor gene, plays a key role in linking behavior, HPA axis- mediated stress responses, and gene expression [2,4].

It is widely accepted that psychological stress affects the immune response, and repeated exposure to a stressor is immunosuppressive. Suppression of immunity is due to anti-inflammatory effects of adrenal glucocorticoid (GC) hormones. Ligation of GC receptors on mononuclear cells suppresses the expression of cytokines, chemokines, and adhesion molecules through a negative regulation of $\mathrm{NFkB}$ activation and function [17-19].

Psychological stress and exposure to the stressor social disruption (SDR) increase cytokine production by monocytes/macrophages and reduce their sensitivity to corticosterone. Splenic monocytes/ macrophages from socially stressed mice are primed to be more physiologically active than nonstressed controls [7,20].

Several studies demonstrating that macrophages are primed during repeated social defeat. In the nucleus, the translocated GC receptors acts as a ligand-dependent transcription factor to modulate the expression of GC-responsive genes, or to suppress activity of other transcription factors, like NFkB $[7,20,21]$.

The links between inflammation, metabolic syndrome, and cancer show that distinct diseases can arise from fundamental abberations in metabolism, homeostasis, and immune function. The advances in systems biology are providing evidence for some of holistic concepts. Diseases are diagnosed based on the epigenetic and psychiatric analysis, then treatment of disease can be in holistic manner too. Treatment regimes are largely designed to restore the potential of organism's natural defence mechanisms and self-healing powers regulated by the principles of psychiatry and epigenetics.

\section{Conclusion}

Also the goals based on early diagnoses of cancer not reduced the level of late-stage disease and decrease cancer mortality. Recent trends and clinical trials show that these goals have not been met. International data demonstrate significant increase in early stage disease, without a proportional decrease in later-stage disease.

The detection and removal of lesions considered precancerous have not led to lower incidence of invasive cancer.

It can be hypothesized, that our methodology must be completed with methods of epigenetics and psychiatry to reveal links between neural, endocrine, immune, social, and psychological brain function. It means use more interdisciplinary effort.

We believe that that the biggest problem of recent life science is its own methodology of over diagnosis. Over diagnosis, if not recognized, leads to overtreatment probably in more than half of clinical cases and significantly contribute to cancer death.

We need to develop a strategy of improving recent approach to cancer screening and prevention. Moreover, in whole life science.

Its time to declare that our old methodologies in life science are absolitizing only temporary, provisional, and short-lived symptoms as definitive diseases. Premalignant conditions should not be labelled as cancers or neoplasia, nor should the word "cancer" be in the name.

We support the idea of reclassification such cancers as IDLE (indolent lesions of epithelial origin) conditions. Temporary states of the organism cannot be absolutisized and rigidly extrapolated as cancer.

We need to use more flexible methods to sufficient treatment of short-lived pathological conditions diagnosed as a disease [5]. This old practice is leading to misuse of billions USD.

Research must include the mechanisms of controlling the environment as an alternative to surgical excision which must be replaced by the less invasive interventions in whole.

The risk of over diagnosis cancer, over threat, screening and patient awareness must be minimize by the use of epigenetic and psychiatric analysis and they must be included into the methodology of cancer diagnosis as its stable part.

We can renew the methodology of cancer treatment outgoing from the principle that stress is not required for mutation, activation 
of the stress response is sufficient. Complementary to the bottom-up approach, bigger role can play also down-stream analysis of a stressresponse-controlled switch to mutagenic pathways. Future research may improve brain links to the potential for social regulation of gene expression in the immune system and its influence on the individual physiology. It will include also to study cancer as the Entropy in Human Brain Networks.

\section{References}

1. Shee C, Gibson JL, Darrow MC, Gonzalez C, Rosenberg SM (2011) Impact of a stressinducible switch to mutagenic repair of DNA breaks on mutation in Escherichia coli. Proc Natl Acad Sci USA 108: 13659-13664. [Crossref]

2. Al Mamun AA, Lombardo MJ, Shee C, Lisewski AM, Gonzalez C, et al. (2012) Identity and function of a large gene network underlying mutagenic repair of DNA breaks. Science 338: 1344-1348. [Crossref]

3. Miller GE, Chen E, Fok AK, Walker H, Lim A, et al. (2009) Low early-life social class leaves a biological residue manifested by decreased glucocorticoid and increased proinflammatory signaling. Proc Natl Acad Sci USA 106: 14716-14721. [Crossref]

4. Tung J, Barreiro LB, Johnson ZP, Hansen KD, Michopoulos V, et al. (2012) Social environment is associated with gene regulatory variation in the rhesus macaque immune system. Proc Natl Acad Sci USA 109: 6490-6495. [Crossref]

5. Esserman LJ, Thompson IM, Jr, and Reid B. (2013) Viewpoint, JAMA, July 29.

6. Hansen KD, Timp W, Bravo HC, Sabunciyan S, Langmead B, et al. (2011) Increased methylation variation in epigenetic domains across cancer types. Nat Genet 43: 768775. [Crossref]

7. Bailey MT, Engler H, Powell ND, Padgett DA, Sheridan JF (2007) Repeated social defeat increases the bactericidal activity of splenic macrophages through a Toll-like receptor-dependent pathway. Am J Physiol Regul Integr Comp Physiol 293: R11801190. [Crossref]

8. Cole SW, Hawkley LC, Arevalo JM, Sung CY, Rose RM, et al. (2007) Social regulation of gene expression in human leukocytes. Genome Biol 8: R189. [Crossref]

9. Cole SW, Mendoza SP, Capitanio JP (2009) Social stress desensitizes lymphocytes to regulation by endogenous glucocorticoids: insights from in vivo cell trafficking dynamics in rhesus macaques. Psychosom Med 71: 591-597. [Crossref]

10. Sapolsky RM, Alberts SC, Altmann J (1997) Hypercortisolism associated with social subordinance or social isolation among wild baboons. Arch Gen Psychiatry 54: 11371143. [Crossref]

11. Whitfield CW, Cziko AM, Robinson GE (2003) Gene expression profiles in the brain predict behavior in individual honey bees. Science 302: 296-299. [Crossref]

12. Grozinger CM, Fan Y, Hoover SE, Winston ML (2007) Genome-wide analysis reveals differences in brain gene expression patterns associated with caste and reproductive status in honey bees (Apis mellifera). Mol Ecol 16: 4837-4848. [Crossref]

13. Chen E, Miller GE, Walker HA, Arevalo JM, Sung CY, et al. (2009) Genome-wide transcriptional profiling linked to social class in asthma. Thorax 64: 38-43. [Crossref]

14. Irwin MR, Cole SW (2011) Reciprocal regulation of the neural and innate immune systems. Nat Rev Immunol 11: 625-632. [Crossref]

15. Sapolsky RM (2005) The influence of social hierarchy on primate health. Science 308 : 648-652. [Crossref]

16. Guo JU, Ma DK, Mo H, Ball MP, Jang MH, et al. (2011) Neuronal activity modifies the DNA methylation landscape in the adult brain. Nat Neurosci 14: 1345-1351. [Crossref]

17. Abbott DH, Keverne EB, Bercovitch FB, Shively CA, Mendoza SP, et al. (2003) Are subordinates always stressed? A comparative analysis of rank differences in cortisol levels among primates. Horm Behav 43: 67-82. [Crossref]

18. Jarrell H, Hoffman JB, Kaplan JR, Berga S, Kinkead B, et al. (2008) Polymorphisms in the serotonin reuptake transporter gene modify the consequences of social status on metabolic health in female rhesus monkeys. Physiol Behav 93: 807-819. [Crossref]

19. Paiardini M, Hoffman J, Cervasi B, Ortiz AM, Stroud F, et al. (2009) T-cell phenotypic and functional changes associated with social subordination and gene polymorphisms in the serotonin reuptake transporter in female rhesus monkeys. Brain Behav Immun 23: 286-293. [Crossref]

20. Szyf M, McGowan P, Meaney MJ (2008) The social environment and the epigenome. Environ Mol Mutagen 49: 46-60. [Crossref]

21. Burmeister SS, Jarvis ED, Fernald RD (2005) Rapid behavioral and genomic responses to social opportunity. PLoS Biol 3: e363. [Crossref]

Copyright: (C2017 Skopec R. This is an open-access article distributed under the terms of the Creative Commons Attribution License, which permits unrestricted use, distribution, and reproduction in any medium, provided the original author and source are credited. 